\title{
Quality Evaluation of Mobile Game: Miftah Alfasaha
}

\author{
Ghada Alhuhud and Wejdan Altamimi \\ Information Technology Department, College of Computer and Information Sciences, King Saud University, \\ P.O. Box 22452, Riyadh 11495, Saudi Arabia \\ Correspondence should be addressed to Ghada Alhuhud; galhudhud@ksu.edu.sa
}

Received 12 February 2016; Accepted 10 April 2016

Academic Editor: Miltiadis D. Lytras

Copyright ( 2016 G. Alhuhud and W. Altamimi. This is an open access article distributed under the Creative Commons Attribution License, which permits unrestricted use, distribution, and reproduction in any medium, provided the original work is properly cited.

\begin{abstract}
Due to evolution of digital games towards mobile platforms, a large exposure to mobile games is nowadays recorded. This is because of the availability of the cell phone with individuals anytime anywhere. Hence, a vital role of game quality assessment is raised. This is for the purpose of serving as a guide for developing healthy games. Accordingly, the mobile games would help in boosting the educational entertainment, healthy diets control, and behavioral sciences studies and research. This paper presents quality assurance and quality models for ISO based educational game. In this paper, an ISO quality model is presented and quality application behavioral impact measures are justified to evaluate the development quality of Miftah Alfasaha game. The quality model and proposed quality assessment plan are tested through a CodePro Analytix tool and six sigma evaluations.
\end{abstract}

\section{Introduction}

Quality assurance and fixed quality models such as ISO software models play an important role in reducing the cost of software development by providing guidelines for quality assurance engineers; moreover software models are helpful to consider an overall understanding of software quality [1]. The ISO quality models consist of characteristics and subcharacteristics that are applicable to both computer systems in use and software products in use [2] that are used to ensure that products meet customer's requirements and the software quality is accepted [3].

Inspired by the revolution towards esocieties and elife, digital games play a significant role in individuals' lives. Recently, wide range of research in the digital games field described diverse aspects regarding development platforms, hardware usability, and usability of digital games after they are put into use [4]. However, the research regarding digital mobile games assessment lacks the clear and identified quality assessment justifiable measures [4]. A lot of software product measures/metrics have been proposed for quality evaluators. However, many of these metrics are produced based on what is important to measure in software and are based on the software type [5]. An ISO/IEC 25010:2011 quality model, presented in [2], is currently widely used to assess the mobile applications; hence, the measures in this model can be used for both assessing mobile games development and usability of mobile games after they are put in use. This paper is organized as follows: background describes the importance of quality assessment of mobile games and the description of our educational game: Miftah Alfasaha that helps Arabic speakers to gain more Arabic vocabularies. Next, the proposed quality model and plan for assessing the described game including a list of policies and procedures (reliability, efficiency, and game maintainability) are presented. Then the quality model was built to wrap up all policies, procedures, and measures. Afterwards, a quality plan with policies, producers, and their measures were tested and analyzed through a CodePro Analytix tool and six sigma evaluations, and experimental results are presented. Finally, a section is devoted to conclusions and recommendations in order to develop a healthy game.

\section{Background}

In this section, the related research in terms of impact of digital games on individual's behaviors, importance of serious quality assessment for digital mobile games, and assessment 
of mobile games developments basics will be presented. In addition, the appropriate quality evaluation tools, six sigma evaluations, will be tackled.

2.1. Impact of Mobile Games on Individual's Behavior. Recall the evolution of digital games industry; games development for mobile platforms is highly demanded. Hence, this would reflect the high presence of digital games in individual's daily activities which would also raise the importance of paying attention to the influence of playing time duration on individual's behavior and health. Accordingly, games on mobile devices have potential to affect the user's health status in terms of excessive use or neural responses; however, it would be a great mean to shape attitudes and beliefs of individuals. Alarming statistics were provided by one of the largest statistics portals: Statista. Statista provides access to relevant data from over 18,000 sources. Figure 1 is obtained from Statista and presents statistical distribution of individual's exposure to digital mobile games in USA during the first quarter of 2014 [6].

\subsection{Importance of Serious Quality Assessment for Digital} Mobile Games. Due to the large exposure to mobile games because of the availability of the cell phone with individuals, a vital role of game assessment is raised in order to help in developing healthy games. In addition, the mobile games would help in boosting the educational entertainment [7], healthy diets control [8], and behavioral sciences [9]. Hence, a great attention should be paid to the important issue which would raise the importance of serious games assessment in these fields. However, evaluating the quality of educational games is not recognized. Existing research focused on evaluating the usability aspects only. In [10], research authors focused on evaluating the effectiveness of the game from an educational aspect. Thus, they performed the study on 90 students and they found that the students' educational performance was improved after playing this game. Moreover, researchers in [11] focused on evaluating usability aspects of the game by developing multiple games and gathering players results for each game. Then they will apply statistical analysis to discover the most preferable game design to the players. After reviewing recent research of games' quality evaluation, we found that there is no study to evaluate the quality of educational games development (codes) instead of evaluating the usability. Thus, this study seems to be the first study that focused on evaluating the development of educational games.

2.3. Quality Assessment Tools for Mobile Games. Usability assessment was one of the most currently published works regarding quality assessment of mobile games. This implies the assessment after the game is put into use. Examples of assessment are presented in [4]. Authors in [4] demonstrated the quality of service provided by the usability studies for egames and focus in these assessments was on the resources available for users regarding network and service providers. However, the work and review provided in [4] express the idea that providing enough resources to specific user does not automatically increase their Quality of Experience (QoE).

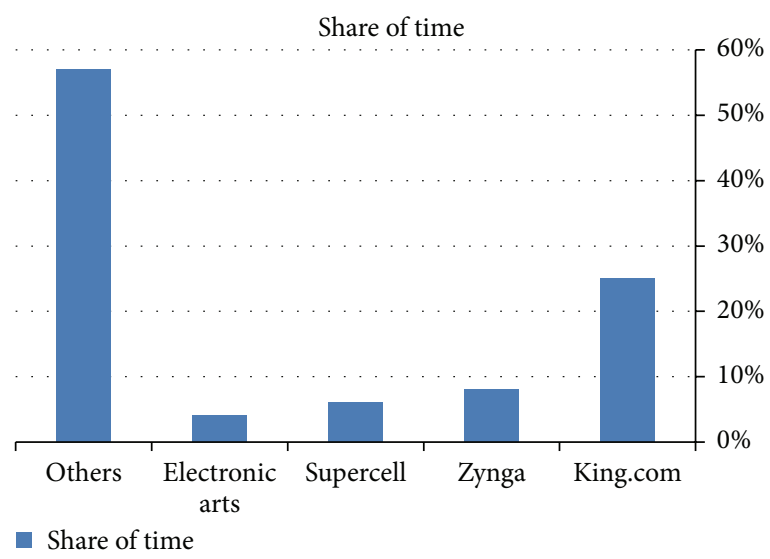

FIGURE 1: Distribution of time spent on Android mobile games in the United States, 2014.

CodePro Analytix is a Java software testing tool for Eclipse developers. It helps them to improve the software quality and reduce developments costs and schedules. The CodePro tool has software auditing features that help the developer to keep track of the quality measures and speed up the product delivery [12].

Six sigma evaluations include process flow charts, run charts, control charts, and capability index. Process flow charts declare the process of quality evaluation for each policy. While histogram and run and control charts are related to the measures and policies results, run charts provide an overview about the measures that were used for more policies and present measures results compared to the standard weights among different policies. Control charts provide an overview about the measures conformance rate for each policy and for all policies. Pareto histogram chart compares all policies and their conformance rate to help in identifying the weakness of the software quality. Using those charts helps quality assurance engineers to find out the quality decencies quickly without reading the detailed report. The last six sigma measure is the capability index (Cpk). Cpk is an index (a simple number) which measures how close a process is running to its specification limits, relative to the natural variability of the process. "The larger the index is, the less likely it is that any item will be outside the specs." Neil Polhemus [7].

\section{Proposed Quality Assessment Framework}

The mobile application under assessment in this paper is an educational entertainment game: Miftah Alfasaha game. This is an educational game that helps Arabic speakers to learn vocabularies in form of engagement game. The game itself was produced by a group of students in the IWAN research group in the College of Computer and Information Sciences.

3.1. Justification for Miftah Alfasaha Game Assessment. Many studies showed that the use of classical Arabic vocabulary and proper sentence structuring has been decreasing significantly for native young Arabs over the last decade. The reason 
for this is perhaps that they find it difficult to describe different conditions and general affairs in a linguistically suitable way. Lexical competence is a term used to refer to the breadth and depth of vocabulary a language speaker knows. For the new, younger generations of Arabic language native speakers, studies show that, with the increasing use of other languages especially in the sciences education domain, the lexical competence of Arabic speakers is decreasing. It is vital for the young generation of Arabs to fully understand and comprehend their native language at a young age to be able to grasp the hidden meanings behind using specific terms in different situations. Although there are a number of Arabic vocabulary teaching mobile applications, the majority focus on low level learning stages, and none of them focus on higher level language. This paper aims to fill this gap by providing a game that enables learning Arabic vocabulary using a new innovative model. This game was developed with Iwan research group at King Saud University; you can find it in Google Play as shown in Figure 1.

3.2. Description of the Game. When the player opens the application, the start page is displayed. It showcases two choices: either to view the help page to read about the game or to play the game. The game consists of a simple multiple choice question form. The player is challenged to find three correct synonyms of the displayed word out of six choices within a time limit. The game is played in levels; there are ten levels, each consisting of five questions and is timed to two minutes and thirty seconds. The level is terminated when the time is up or all the questions are answered. Afterwards, the result page is displayed showing whether the player passed or failed the level. The player can pass a level by answering at least half of the questions correctly. Here are some screen shots of the game; see Figures 2 and 3.

3.3. Quality Model and Plan. In order to ensure the quality of Miftah Alfasaha game development, there are a number of policies to ensure the system quality and to guarantee continual improvements. These policies are the following:

(a) Reliability: Miftah Alfasaha game operations should be failure-free whenever player progressed in levels to ensure that player's points and answers are kept. So, this policy can be achieved by ensuring game recoverability and can be tested by the following measures: Coupling Between Objects (CBO) and Weighted Methods Per Class (WMPC). These measures are so important in evaluating the quality of mobile game development. This is because of the importance of not stimulating the anger and negative reflexes regarding the recoverability of the game.

(b) Efficiency: the level of performance of the Miftah Alfasaha game should be high to respond in very short time and give the players the sense of hurry; this policy can be achieved by ensuring a time behavior and can be monitored through Coupling Between Objects $(\mathrm{CBO})$ measure. This measure is considered crucial in terms of identifying the user's speed of the

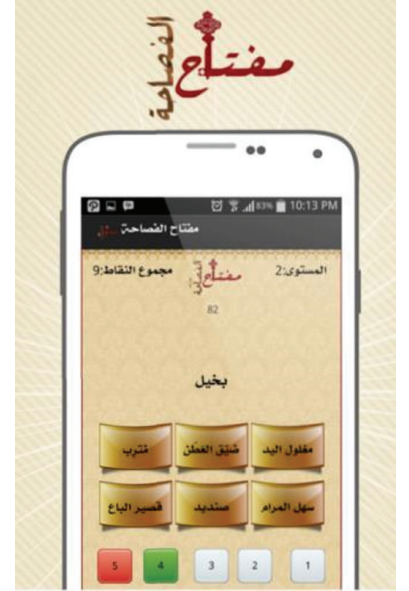

Figure 2: Miftah Alfasaha interface.

neural responses and hence the attitude related to hard and rush actions.

(c) Maintainability: the Miftah Alfasaha game should be editable so it can be improved and include more levels or changed easily. So, this policy can be achieved by monitoring game testability. To ensure the testability, three measures were chosen: Weighted Methods Per Class (WMPC), Comments Rate (ComR), and Abstraction Rate (AR). After establishing required policies, the quality model is built as you can see in Figure 3.

To evaluate those policies and procedures, quality plan was created. The quality plan defines policies and procedures weights and prioritized them based on Miftah Alfasaha game requirements. The priority of policies compliance is ordered as the following:

(1) Reliability (0.40).

(2) Efficiency (0.30).

(3) Maintainability (0.30).

Due to the criticality of the Miftah Alfasaha game context (learning context), the players during the game need highly reliable game to ensure that no points will be lost and no correct answers will be discarded. The second policy is efficiency to ensure fast responses to players' actions. The last policy is maintainability of the game which is less important than reliability and efficiency. The quality plan is shown in Table 1.

\section{Experimental Results}

The evaluation of Miftah Alfasaha game was done from two aspects. The first aspect is testing the code measures by CodePro tool. The second aspect is performing six sigma evaluations. The following subsections present the evaluation results based on the quality plan. 


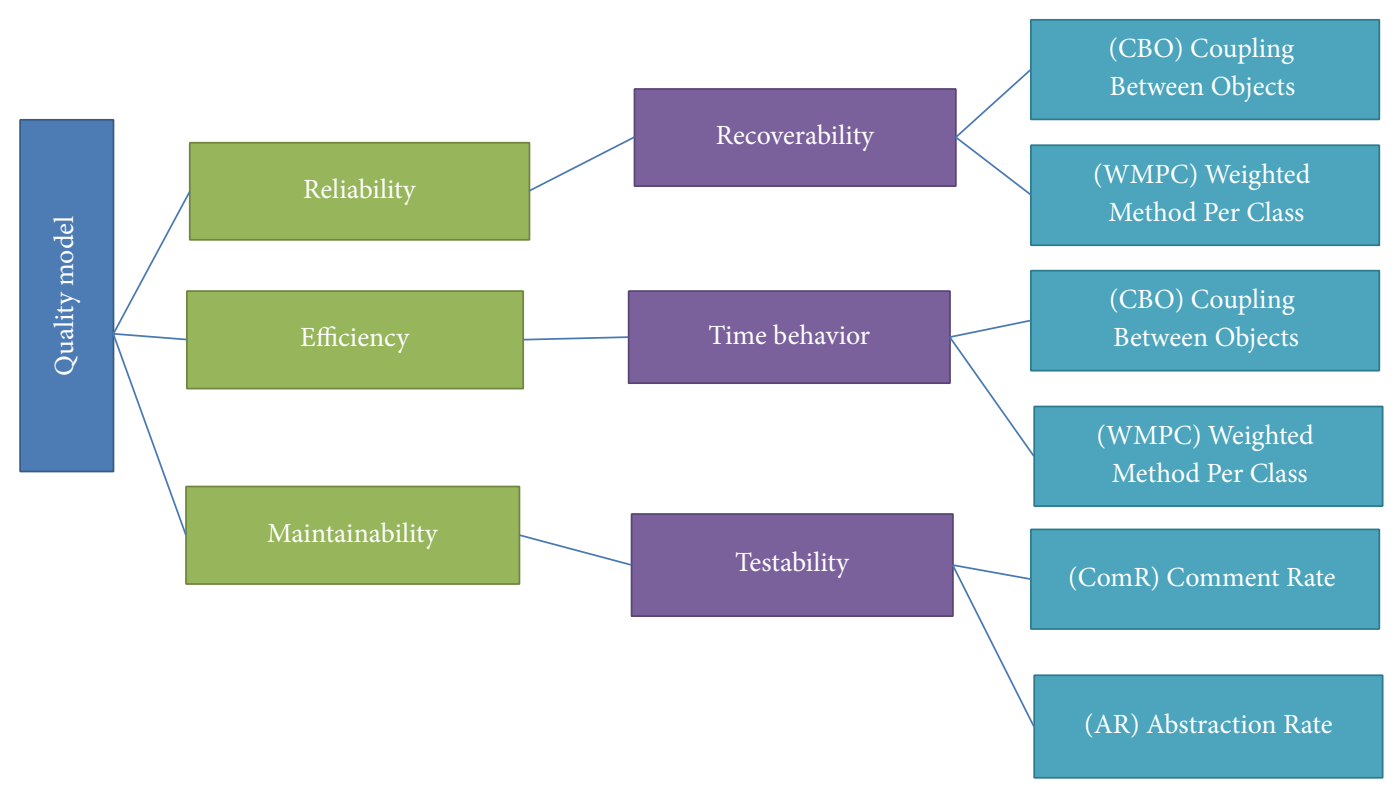

FIgURE 3: Quality model.

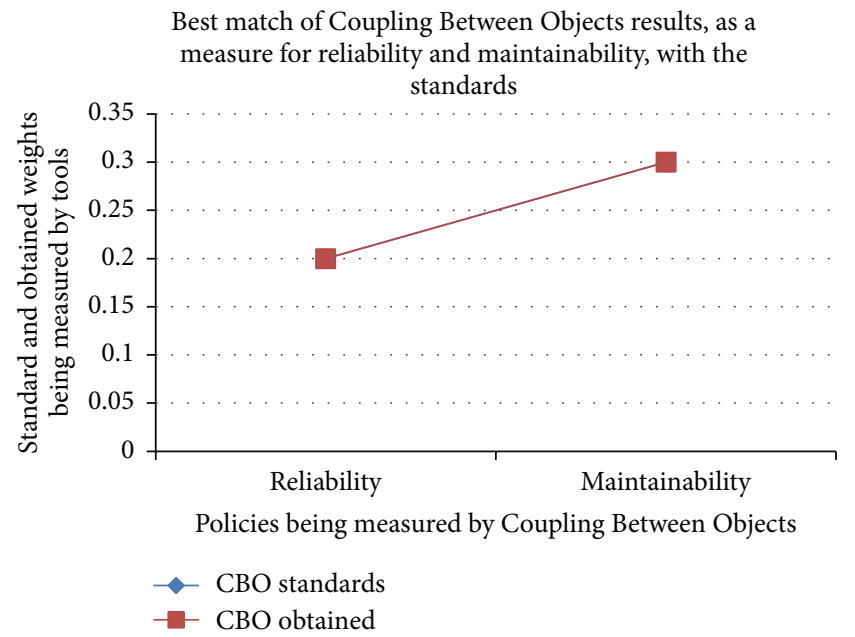

Figure 4: Run chart for CBO measure overall policies.

4.1. Game Quality Assessment Results Using CodePro. The quality plan was followed and the conformance rate was calculated for each measure; then it is calculated for the policies as well. Table 2 shows the results of all measures and the conformance rate of all policies.

4.2. Six Sigma Evaluation. Six sigma quality assessment is performed through calculating the measures and presenting them in run charts, control charts, histogram charts, and the capability index (Cpk). Here, we will provide a summary for each measure:

(i) Run charts were created for CBO and WMPC since they were used for many polices. And all those measures are within the standards; then they are given

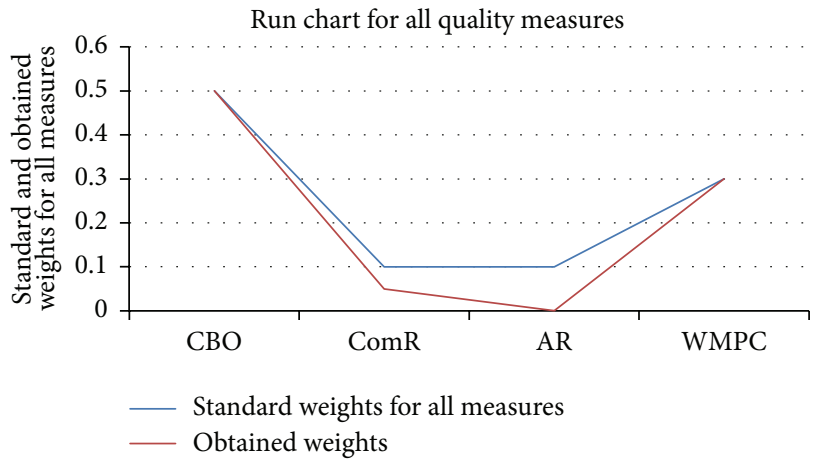

FIGURE 5: Control chart for all measures.

the full weights. Figure 4 represents the run chart for $\mathrm{CBO}$ measure as sample.

(ii) Control chart was created for each policy to compare its measures compliance and also it was created for all used measures (Figure 6). As you can see in Figure 5, two measures got the full weight while the recent are not given the full weight.

(iii) Pareto histogram: after evaluating the policies, a histogram chart was created to summarize policies compliance as shown in in Figure 7; we found that Miftah Alfasaha game does not have problems in its efficiency and reliability. However, it has a problem in its maintainability.

(iv) Capability index (Cpk): the capability index for each measure was calculated and Table 3 summarizes the results of six and three sigma for each measure. Then we get the full weights. Moreover, Figure 7 shows the measures complaints for maintainability policy as sample. 


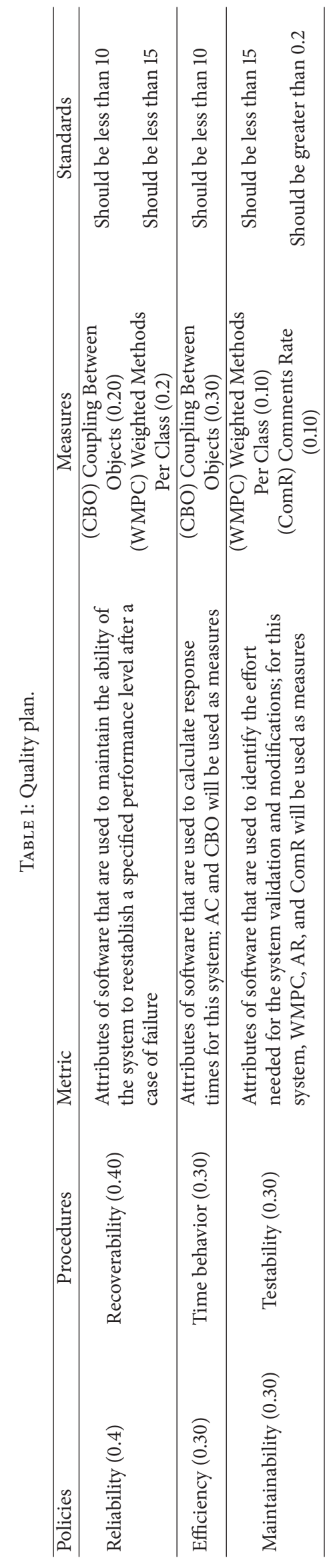




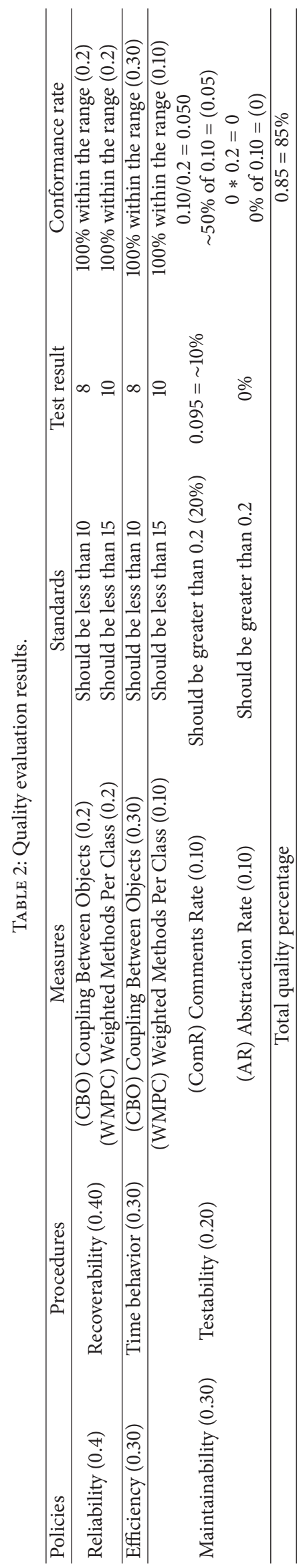


TABLE 3: 3 Sigma capability index results.

\begin{tabular}{lccc}
\hline Measure & Six sigma & Standard compliance & Sigma compliance \\
\hline $\mathrm{CBO}$ & $\mathrm{Cpk}=\min \{1.6$ or 0.83$\}$ & CBO is within standard value & Cpk $<1$ \\
WMPC & $\mathrm{Cpk}=\min \{1$ or 0.53$\}$ & WMPC is within standard value & Not compatible with 3 sigma \\
\hline
\end{tabular}

TABLE 4: 6 sigma capability index results.

\begin{tabular}{lccc}
\hline Measure & Six sigma & Standard compliance & Sigma compliance \\
\hline ComR & Cpk $=\min \{0.23,0.83\}$ & ComR is not within standard value & $\begin{array}{c}\text { Cpk } \\
\text { Not compatible with } 6 \text { sigma level }\end{array}$ \\
\hline AR & Cpk $=\min \{0.098,0.34\}$ & AR is not within standard value & Cpk \\
\hline CBO & Cpk $=\min \{0.83,0.41\}$ & CBO is within standard value & Cpk $\begin{array}{c}\text { Is compatible with } 6 \text { sigma level. } \\
\text { WMPC }\end{array}$ \\
\hline Cpk $=\min \{0.5,0.26\}$ & WMPC is within standard value & Is compatible with 6 sigma level. \\
\hline
\end{tabular}

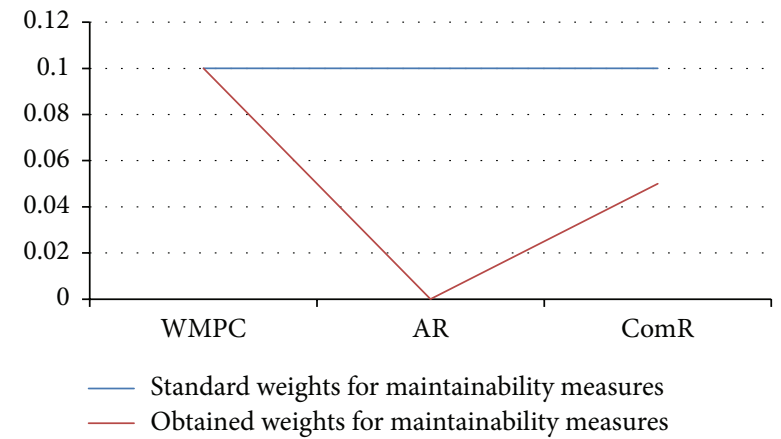

FIGURE 6: Control chart for maintainability policy.

As one can see from Table 3, ComR and AR measures are not compliant with six sigma level, and that is consistent with their standards compliance since ComR and AR values are not within standard values. However, even though the values of $\mathrm{CBO}$ and WMPC are within standard values, they are not compatible with the six sigma level. Therefore we calculate the three sigma for them as seen in Table 4. From Table 4, it is clear that the results are very close to 1 , but because of the restrict capability index equation, the $\mathrm{CBO}$ and WMPC also were considered to be not capable with 3 sigma level. And that gives us an indication about the importance of collaborating quality evaluation based on defined quality model and six sigma evaluation.

\section{Conclusion and Recommendations}

In this paper, the quality of Miftah Alfasaha game is evaluated by developing a quality model that includes suitable policies, procedures, and measures. Hence, the paper identifies the conformance rate for these measures according to the ISO standards. Six Sigma evaluations also were applied. The

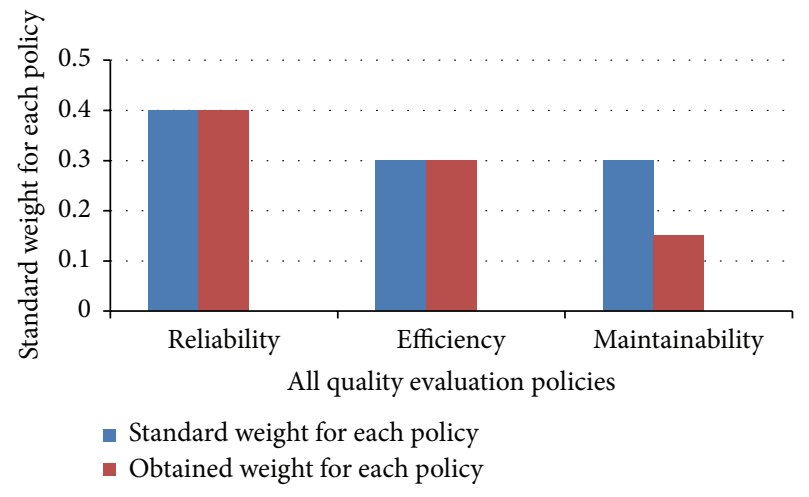

Figure 7: Pareto histogram for policies compliance.

results indicate that the overall quality percentage for the game is $85 \%$ which is a good percentage in terms of speed of game responses as well as the recoverability of the game. It has an excellent level of efficiency and reliability. Finally, Miftah Alfasaha game is as many powerful educational or healthy games and requires guided and careful quality assessment concerning the behavioral influence of the long time exposure of user to the game. This research recommends that a great attention should be paid to the mobile games development in terms of (1) careful calculations and assessment of the time behavior of the system; (2) recoverability of the game after failure occurrence; (3) compatibility across different platform development environment so as to serve IOS/Android integration that would support the maintainability in the future.

\section{Competing Interests}

The authors declare that they have no competing interests. 


\section{Acknowledgments}

This research was supported by a grant from the Research Center of the Female Scientific and Medical Colleges, Deanship of Scientific Research, King Saud University.

\section{References}

[1] D. Houston, "Software Quality-ASQ," Asq.org, 2015, http://asq .org/learn-about-quality/software-quality/overview/overview .html.

[2] ISO/IEC, "Systems and software engineering-systems and software quality requirements and evaluation (SQuaRE) system and software quality models," ISO/IEC 25010:2011, 2015, http://www.iso.org/iso/catalogue_detail.htm?csnumber=35733.

[3] Iso.org, "ISO 9000 quality management-ISO," 2015, http:// www.iso.org/iso/home/standards/management-standards/iso_ 9000.htm.

[4] M. Matulin and Š. Mrvelj, "State-of-the-practice in evaluation of quality of experience in real-life," Environmentsint Journal of Traffic \& Transportation, vol. 25, no. 3, pp. 255-263, 2013.

[5] C. Ruan and J. Yang, "Software quality evaluation model based on weighted mutation rate correction incompletion G1 combination weights," Mathematical Problems in Engineering, vol. 2014, Article ID 541292, 9 pages, 2014.

[6] Mobile Internet Applications, April 2016, https://www.statista .com $/$ search $/$ ?statistics $=1 \&$ forecasts $=1 \&$ dmo $=1 \&$ studies $=1 \&$ industryReports $=1$ \& topics $=1$ \&infos $=1$ \&interval $=0$ \& categor $y=0$ \& subCategory $=0 \% \mathrm{C} 2 \%$ AEion $=0$ \&archive $=1 \& \mathrm{q}=$ distribution + of + mobile+games+playing+time\&sortMethod=idrelevance\&accuracy $=$ and \&itemsPerPage $=25 \&$ subCategory $=0$.

[7] sixsigma.com, "Six Sigma Resources for Six Sigma Quality," 2015, http://www.isixsigma.com.

[8] T. Baranowski, D. Thompson, R. Buday, A. Shirong Lu, and J. Baranowski, "Design of video games for children's diet and physical activity behavior change," International Journal of Computer Science in Sport, vol. 9, no. 2, pp. 3-17, 2010.

[9] T. Baranowski, J. Baranowski, D. Thompson, and R. Buday, "Behavioral science in video games for children's diet and physical activity change," Journal of Diabetes Science and Technology, vol. 5, no. 2, pp. 229-233, 2011.

[10] M. Virvou, G. Katsionis, and K. Manos, "Combining software games with education: evaluation of its educational effectiveness," Educational Technology and Society, vol. 8, no. 2, pp. 5465, 2005.

[11] S. Malatini and A. Bogliolo, "Gamification in mobile applications usability evaluation," in Proceedings of the 17th International Conference on Human-Computer Interaction with Mobile Devices and Services Adjunct (MobileHCI '15), Copenhagen, Denmark, August 2015.

[12] Google Developers, “Code Pro Plugin,” November 2015, https:// developers.google.com/java-dev-tools/codepro/doc/. 

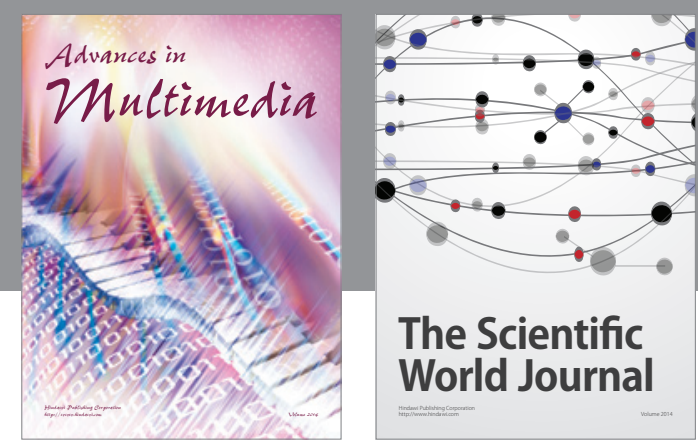

The Scientific World Journal
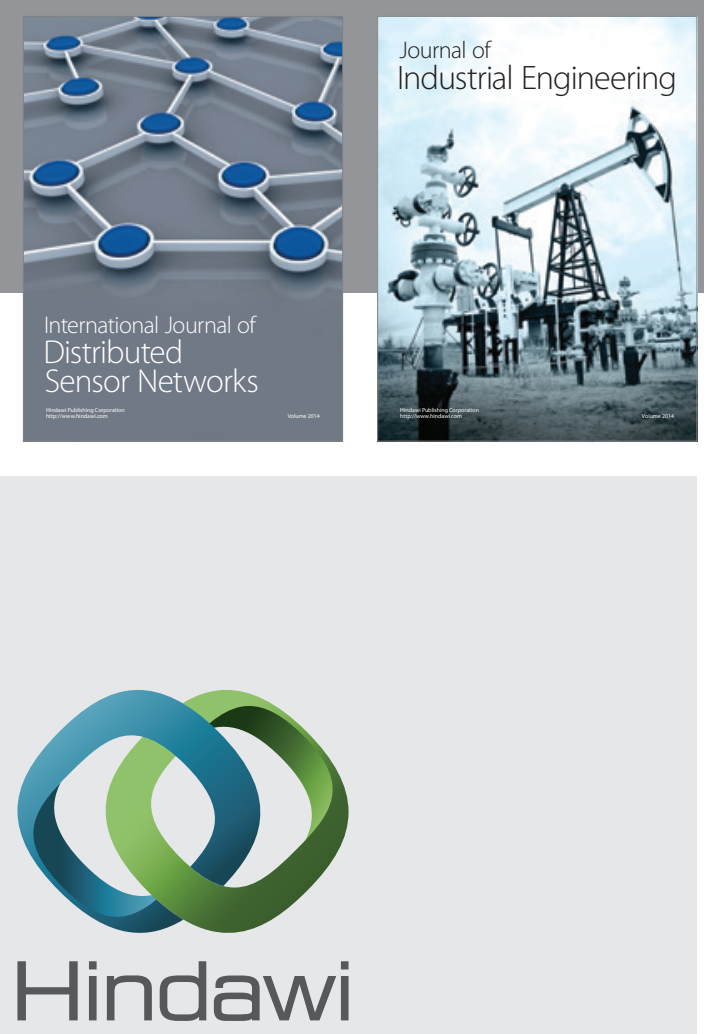

Submit your manuscripts at

http://www.hindawi.com

\section{Computer Networks} and Communications
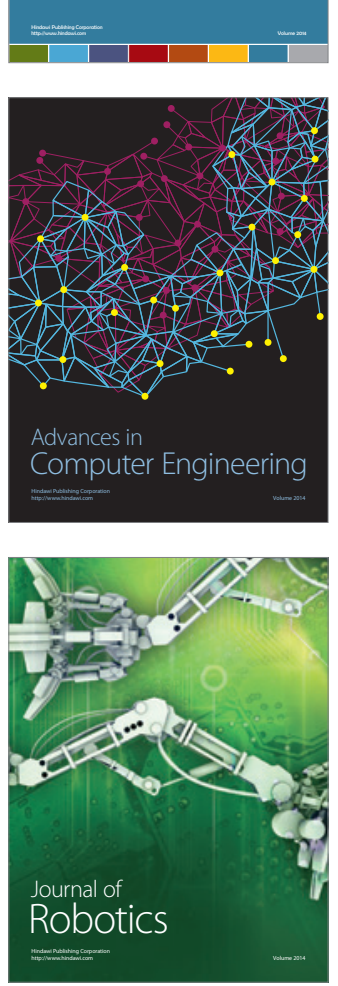
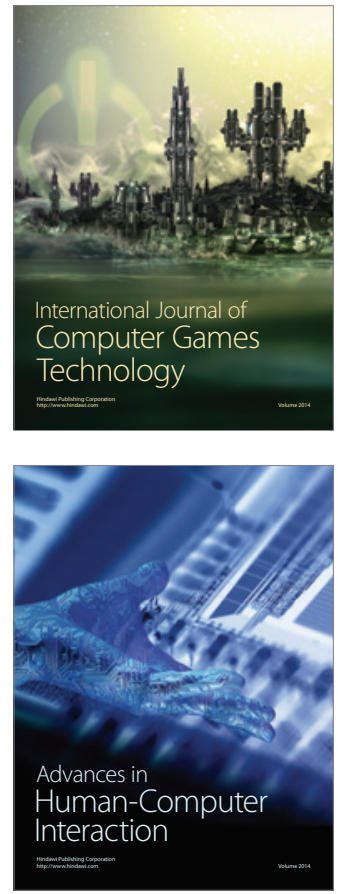
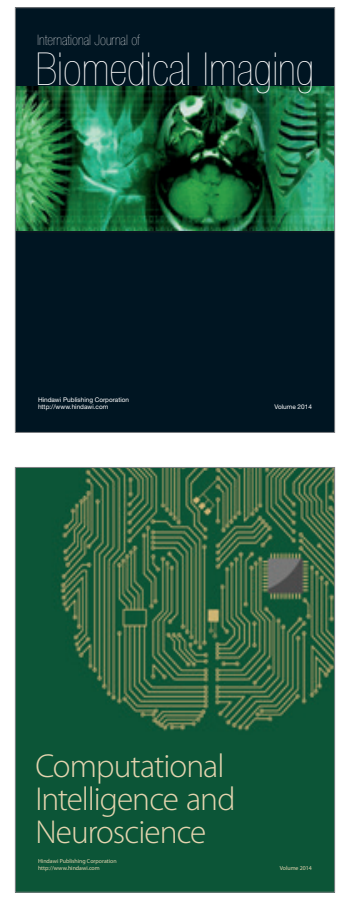
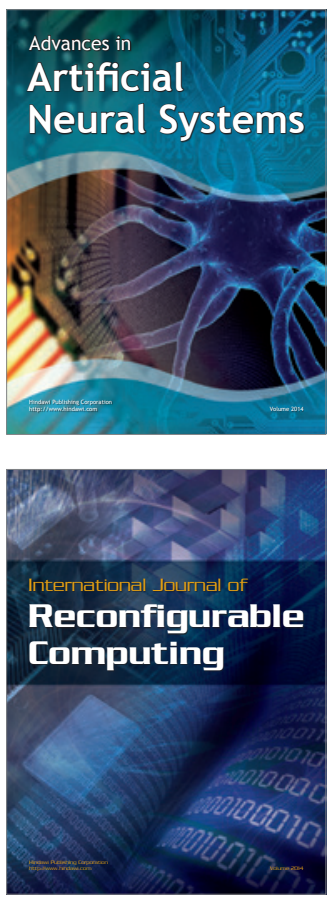
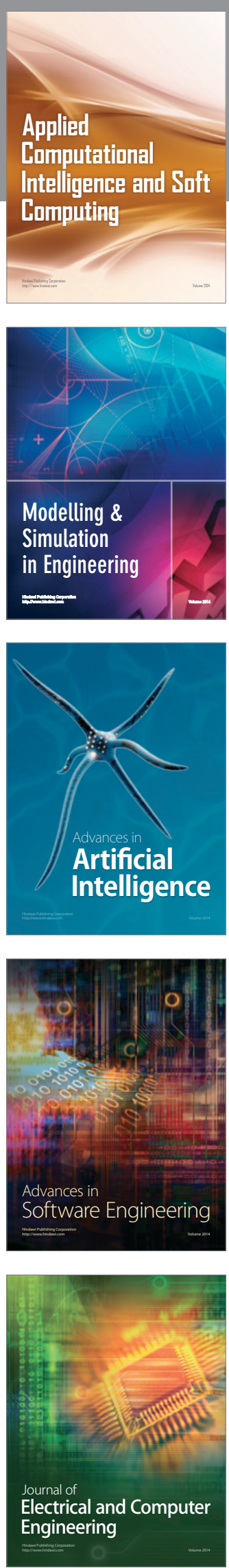